\title{
Ergonomics in projects of oil platforms in a change context
}

\author{
Barbara Oggioni $^{\mathrm{a}}$, Francisco Duarte ${ }^{\mathrm{a}}$ and Cláudia Cordeiro ${ }^{\mathrm{a}}$ \\ ${ }^{a}$ Production Engineer Department, Federal University of Rio de Janeiro (COPPE/ UFRJ), Post Office Box 68507, \\ zip code 21941-972, Rio de Janeiro, Brazil (www.ergonomiaeprojetos.pep.ufrj.br - ergoeproj@pep.ufrj.br).
}

\begin{abstract}
The context of oil platform design is changing in order to increase competitiveness and be prepared for difficult operations, mainly in fields more distant from the coast, like pre-salt. The currently preceding context is marked by projects guidelines designed to reduce projects and operation costs, including an important reducing in the number of people on board. The main objective of this research is to verify and discuss if the experience of use in platforms designed in a previous context, in which the people on board is practically twice, can contribute and/or can be transferred to new projects. From the ergonomic intervention in the design of two oil platform, with the work of team on board investigated on previous projects as reference, it was possible analyze if the previous use is still applicable to new projects. As a result, about $90 \%$ of the recommendations based on use are applicable to the current context. The restrictions on the transfer or operational experience are mainly related to the time of entry of ergonomics in the design process, the subsequent transformations costs and the advance of the execution phase started with the detailed design.
\end{abstract}

Keywords: Ergonomic, Design, Oil platform, Accommodation, Change context.

\section{Introduction}

The current context of projects of oil rigs has being modified, representing a major challenge in the design of these units from the end of the year 2000. To rise competitiveness and be prepare for the difficulties of deep water operation and extraction environments distant from the coast, the seek for concise projects is a fact, characterized by the reduction of the population on board, reusing existing houses and new modes of retaining offshore. These, among other measures, are strongly inspired on marine platforms chartered, projects that have desired characteristics in terms of costs and project time. The preceding projects is marked by different guidelines, which have mostly construction of new houses and a higher number of population on board, almost a double of what is needed in projects today.

Under this context, a research question can be done: the experience of previously platforms designed on the basis of different guidelines, and consequently in a previous context, can serve as a basis for the design of platforms in the current context?
According to [2], the knowledge of the reality of work is becoming a strategic dimension for the success of projects. In this sense, the practice of ergonomics in design phase is, therefore, necessary to provide information, technical and organizational choices, placing the probable consequences on the future conditions of work. The ergonomics design leads to design practice focused on real activity.

To answer the previous question, this research is based on a theoretical reference about ergonomics and design, in chapter 2 , which introduces the integration approaches of ergonomics in design; in a methodological approach presented in chapter 3; and in a field work in chapter 4: the ergonomic intervention in the project of two oil rigs inserted in the new orientation of the project, and, consequently, with differentiated characteristics as the number of POB reduced and reusing the hamlets of ships. Finally, the chapter 5 presents the discussion and conclusion. 


\section{Ergonomics contribution to design}

The design, a cognitive activity, is present in all professional activities related to the project. For [6], conceive is pursuing an intention, to consider a change to operate. In the design process there is a goal, following a direction, a sense. Design is also transform, drive and perform a change oriented.

According to [6], "the design processes do not take enough care about the functioning of human beings, or the activity that they develop when use devices or operating production systems". And one of the ways in which these factors may be considered and integrated into the design process is through integration of ergonomics in the design process.

[11]describes two goals of ergonomics, in which lies his specificity. One is centered in organizations and in their performances, that can be seized under different aspects: efficiency, productivity, reliability, quality, durability, etc. The other is centered on people, also disposed in different dimensions, such as safety, health, comfort, ease of use, satisfaction, interest in work, pleasure, etc.

This duality of objectives is well represented by the ergonomics of the activity from French origin. For [5], the ergonomic action aims first the transformation of work in order to contribute to the design of situations that do not adversely affect the health of operators and achieve the economic goals determined by the company, in the light of the current or future investments. These two goals can be complementary, taking into account the procedure that considers interaction between two logical; one focused on the social and another in production.

For [7], speak about activity is, first of all, define a unit of analysis to understand the professional practices. Job activity has focused on worker as an intelligent agent who owns and share professional skills developed during his experience, acquiring the ability to regulate, coordinate and build their conduct to achieve a goal. But these adjustments and coordination not start from zero, the activity is situated within a given context from social and historical materials, components, which in addition to provide the resources, also defines constraints. Simultaneously, this context is affected by the life experience of a subject, and is, therefore, constantly revised and redrafted.

There is a variety of possible perspectives about the situation of the activity in the design, and these different perspectives guide the insertion of ergonomics in design and, consequently, the professional practice of the ergonomist. Thus, it is possible to dis- tinguish three different perspectives: crystallization, plasticity and development, where a dialogic model design fits as an articulator of different orientations $[7,8,9,10]$. Each of these approaches will be followed presented.

In crystallization, any technical device, each artifact, "crystallizes" a knowledge, a representation, and, in a broader sense, a user template, your activity and your work. But once crystallized in the artifact and served in work situations, this template can be a source of numerous difficulties for users if they are false or incomplete [8].

The contribution of ergonomics, therefore, is in fact its ability to enrich and even transform these representations and implied models that designers mobilize on their work [8].

In plasticity, according to [7], the reality of actual work always goes beyond the built model. For this reason, second [4], to engage in design, ergonomics needs to provide "the space of possible forms of future activity", i.e. it is necessary to take into account the contingencies of the situation and develop technical systems that make the easy adaptation susceptible of future work [7].

The development approach adds features enjoyed the previous guidelines, but this approach adds a further dimension: the development of the artifact and the development of the activity must be considered together during the configuration of a project. This way, the challenge is to articulate, within the same movement, the design of artifacts to the designers and the development of resources their own actions by operators [7].

According to [8], the introduction of a new technique enables to solve old problems for which new forms of action will be necessary, getting clear on the question of possible developments or impossible of activity and not only the development of new technique.

These different approaches do not cancel each other; however, they can be complementary, representing an evolution in how ergonomics is considered in design. It is ideal that ergonomic can contribute to design through the use observed in reference situations. In this sense, the notion of setting of use can bring the work perspective to the project. Without defining or detailing the project, the objective of this kind of setting is to produce configurations extracting the existing relations with spaces from the observed situations during the activity follow-ups. This way, information about use is provided to the designer as well as its implications for envi- 
ronment design, without presenting a final solution for each space [1].

\section{Methodology to analyze offshore accommodations design}

Contextualized in the continuity of the project "Integration of ergonomics to offshore platform design" [3], conducted by the Program of Product Engineer at COPPE/ UFRJ and the Research Center of a Brazilian company of oil exploration and production. The goal of this project was to systematize the accumulated experience in the operation of offshore platforms, generating, from the lessons learnt, ergonomic recommendations for the accommodation module and also for the process area of oil platform, bringing the principles of work situations reality for future designs.

From the data obtained in that project, we sought to verify the applicability of recommendations based on the real conditions of work for the projects of oil platforms that existing houses and that have arisen in the current context of changing design guidelines.

For this, the project of two oil platforms, type FPSO, was used as a case study. These platforms had as main features the reuse of old ships, the POB reduced, and phases of construction to be carried out in different and distant countries, in Brazil and abroad.

The ergonomic study of the project of these platforms was intended to generate recommendations for the phase of detailing and construction of the project in two distinct phases. The first, held in an overseas country, covered all the compartments of the area of accommodations, such as the galley, mess room, hospital, provision stores, cabins, restrooms \& change rooms, laundry, gymnasium, helilounge room, entertainment rooms and auditorium.

The second phase had the aim to generate recommendations for the project detailing and execution in Brazil, considering the control room, radio and TELECOM room, workshops, warehouses, store-rooms, laboratory, and the electrical and instrumentation panels.

The time of ergonomic study entry in the stage of detail is an important factor for understanding its activities, since the scope to implement the recommendations were reduced because of the progress of the project and because of the simultaneous implementation of detailing and construction activities.

From the usage-based recommendations for the design of housing environments on oil rigs [3], was reviewed and understood the basic design of two platforms, with the objective to match the initial layout characteristics of the activity performed in these environments.

At that understanding stage of the project, the main difference between the initial project and recommendations, based on usage observed in reference situations in [3], were detected. These differences between the planned for the project and the current use were classified as: problems related to location, accesses and flows; the sizing and layout; and the furniture, equipment, devices and installations.

From the analysis and classification of problems according to the needs identified, each environment studied with the reality of project platforms P-A and $\mathrm{P}-\mathrm{B}$ are allowed to build knowledge of the project and of its restrictions, leading to an evolution in the proposals of layout modifications.

It is important to note that, even though the recommendations could not be applied due to restrictions and specific characteristics of the project of two platforms, the ergonomic suitability attempts have taken as a primary reference the use in each place of accommodation module. The participation of various actors - users and designers - also contributed to a better understanding of particularities that should be taken into consideration.

\section{The mapping of the experience of previous use in the current context of projects}

The analysis of the ergonomic study evolution for the two platform projects aims to support the discussion around possibility of using ergonomic recommendations based on experience of working platforms designed on a previous context. ie. to transfer the use experience, translated into recommendations for the ergonomic design of accommodations of P-A and P-B. On this way, the types of environments, firstly, were grouped into sectors: food, rest, leisure, and operation.

For each environment, the use of ergonomic recommendations in the project has been mapped. The analysis of the use and possibility of using the ergonomic recommendations allows an understanding of the efforts to resolve the differences between what was initially designed in the basic design and what the work activity performed in these environments demand in practice. The following is an example of this application to the control room design of the platform projects studied. 


\section{Control room design}

The control room activities are continuous and are related to remote operation of production, facilities, automation and navigation (for vessels) systems. The operators activities include the permanent monitoring system about the operation variables, operating in specific adjustments that must be performed by automated system or by field operators.

The support areas for control room - as offices, meeting rooms, videoconference room, technical library, snacks room and toilets - are essential to give appropriated support to operators. The proximity of these rooms with each other and with control room is important, not only in daily contacts, but specially in crisis situations, when the need for interactions of technicians and engineers with the operators is larger and more frequent.
According to [3], the settings of use that must be fulfilled in the control room design area is listed in the table 1 .

From the understand of the setting of use in this environment, the figure 1 shows the possible utilization of ergonomic recommendations, also found in [3], for control room and support areas design, considering location, access, flows, layout, furniture and equipments.

These ergonomic recommendations were classified to allow further discussion of its use in accommodation platforms design in a change context. This classification is: (1) viable application; (2) viable application, but not applied; and (3) unfeasible application. As the graph shows, there were difficulties in using the recommendations related to the location of places, due to cost changes that could be generated in this project phase, and there were difficulties related to layout, because of the restriction caused by the reuse of house ship.

Table 1 - Control room settings of use

\begin{tabular}{|c|c|c|}
\hline Use & Local & Description \\
\hline General use & $\begin{array}{l}\text { Operation room } \\
\text { (operation console) }\end{array}$ & $\begin{array}{l}\text { Monitoring, control and operation of valves, devices and equipment remotely and in constant com- } \\
\text { munication with field staff. }\end{array}$ \\
\hline Shut down & $\begin{array}{l}\text { Operation room } \\
\text { (operation and fa- } \\
\text { cilities console) }\end{array}$ & $\begin{array}{l}\text { The platform generators run on gas. When there is a break in gas production and the "process plant } \\
\text { falls", the generators must operate on diesel. In this situation, the facilities team must starts the } \\
\text { generators for the production team will once again operate, resend gas to generators and, from there, } \\
\text { re-stabilize production. This may necessitate the presence of supervisors and in some cases, coordi- } \\
\text { nation of the unit there is a strong interaction between production and facilities teams in the control } \\
\text { room. }\end{array}$ \\
\hline Offloading & $\begin{array}{l}\text { Operation room } \\
\text { (operation and ma- } \\
\text { rine console) }\end{array}$ & $\begin{array}{l}\text { In a situation of discharge of oil (offloading) maneuvers are performed by a marine team, since the } \\
\text { emptying of a tank causes the unit imbalance. Production and marine teams of control room are in } \\
\text { communication throughout the process, so that oil production is distributed in the storage tanks, } \\
\text { delivering a balance of loads. }\end{array}$ \\
\hline $\begin{array}{l}\text { Transfer water } \\
\text { for vessel } \\
\text { tanks }\end{array}$ & $\begin{array}{l}\text { Operation room } \\
\text { (operation and ma- } \\
\text { rine console) }\end{array}$ & $\begin{array}{l}\text { When the water used in production is treated and does not reach the suitable levels of waste } \\
\text { oil and grease (TOG) for disposal at sea, this water is diverted to a tank vessel, to be discarded } \\
\text { by offloading. In this case, there is a strong interaction between the vessel and production } \\
\text { teams in order to perform the maneuvers and ensure that residue levels return to normal. } \\
\text { If the water volume exceeds the tank capacity, it is necessary to transfer this water to oil tanks. } \\
\text { When this occurs, there is loss of oil deposited in the tank and possible damage to the tank due to } \\
\text { corrosion caused by water. }\end{array}$ \\
\hline $\begin{array}{l}\text { Adjustments } \\
\text { in the reading } \\
\text { of sensors }\end{array}$ & $\begin{array}{l}\text { Operation room } \\
\text { (operation/ facilities } \\
\text { and automation } \\
\text { console) }\end{array}$ & $\begin{array}{l}\text { When operators of production or facilities identify a discrepancy between the reading of automatic } \\
\text { sensors and the actual measurements reported by field operators, it is necessary the intervention of } \\
\text { the automation team to make the necessary adjustments and re-establish the correct readings. In } \\
\text { these cases, the automation technical joins the production or facilities operator in their respective } \\
\text { consoles. }\end{array}$ \\
\hline $\begin{array}{l}\text { Issuance of } \\
\text { work } \\
\text { permission }\end{array}$ & Operation room & $\begin{array}{l}\text { Maintenance activities must be authorized by the field operator responsible for the area where the } \\
\text { service will occurs, through the issuance of a PT. For this, it is necessary filling some documents } \\
\text { and, if there is any kind of risk, need to fill appointments to the system via computer or, in some } \\
\text { situations, evaluation of other sectors. If there is no support for this activity, which is daily, the } \\
\text { control room will be used, which generally disrupts the operation environment. }\end{array}$ \\
\hline $\begin{array}{l}\text { Administrative } \\
\text { activities }\end{array}$ & $\begin{array}{l}\text { Operation room } \\
\text { (operation console) }\end{array}$ & $\begin{array}{l}\text { The administrative activities of supervisor responsibility are held in the consoles, temporarily occu- } \\
\text { pying the administrative computer operation, since in some situations, there isn't a workstation for } \\
\text { the supervisor. }\end{array}$ \\
\hline
\end{tabular}




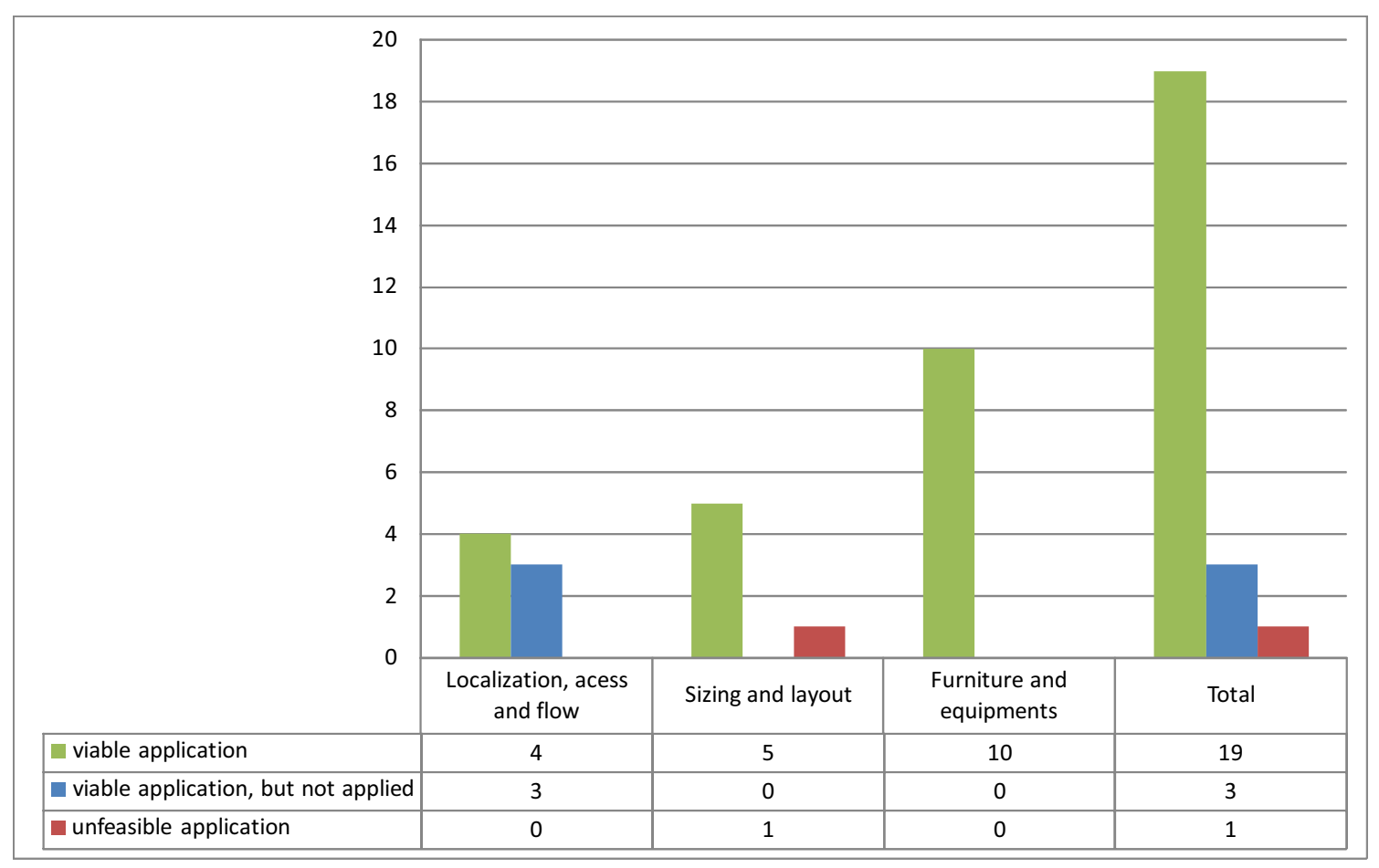

Fig. 1 - Possible utilization of ergonomic recommendations in control room design

\subsection{Reflections from the choice of ergonomic design solutions}

The participation in design process as ergonomist and the validation of their stories with project actors (architects) led a discussion about the layout suggested by the ergonomic study and chosen by the client company. Thus, it was possible to identify the main points of difficulty of recommendations implementation based on the use of previous experiences. From this reflection, it was possible to categorize these "whys" as follows:

Detailing and construction phase tied to basic design. Contractually, "the project was very tied". The company responsible for detailing and construction "obeyed the basic design, because the contract sad for him to follow the basic design", and any change would generate additional costs.

From this contract feature, the project managements of each platform evaluated if the proposed changes were feasible and what were the impacts of costs incurred.

Simultaneity between the detailed design and construction. "You are detailing the project and the con- struction is happening at the same time". There was, therefore, simultaneous steps of detailing phase and construction as result of a narrowing of the project phases, using the basic design as a source of data for the construction.

Guidelines and design parameters. Besides the new policy or new "design philosophy" that came to govern the platform projects, for P-A and P-B projects were used "fuses parameters" too, which serve as indicators for the project: if any parameter is exceeded, it is an indicator that the "fuse" would be breaking. "So you have to walk in the straight road, any deviation from what you have to do, this indicator puts you back on the way."

Each discipline had its "parameters fuses", mostly involving limitations to reduce costs. In the case of architecture and ergonomic study, there were two such parameters: all accommodation spaces had to have an occupancy rate of one person for each $19 \mathrm{~m}^{2}$ up to, and control room area could not exceed $74 \mathrm{~m}^{2}$. Consequently, all habitable areas were limited to the basic design and it was not possible to change or increase the area per occupant. Therefore, any proposed extension was refused in the beginning of the ergonomic study. 
Another difficulty for the ergonomic study analyzes the control room design was the lack of work organization definition. To overcome this, the ergonomic study was based on the organization used in the reference units. The proposed arrangement was reviewed and subsequently reorganized by future operators. After this analysis, the proposed layout has been redesigned by the client company, maintaining the equipment and furnishings suggested.

\section{Practice reflection and conclusions}

The reflection about the stories of ergonomic intervention in accommodation module design - where the ergonomic study proposed solutions based on the settings of use and on the recommendations generated from that use - allowed identifying the possibility of ergonomic information transfer to new projects. By understanding the settings of use in each room and apply the ergonomic recommendations, both generated in [3], it was possible to analyze its use in the design process and evaluate whether they are still applicable to new projects in different contexts. The figure 2 shows a graph of the mapping of the ergonomic recommendations utilization for all areas of accommodation module in the studied projects.

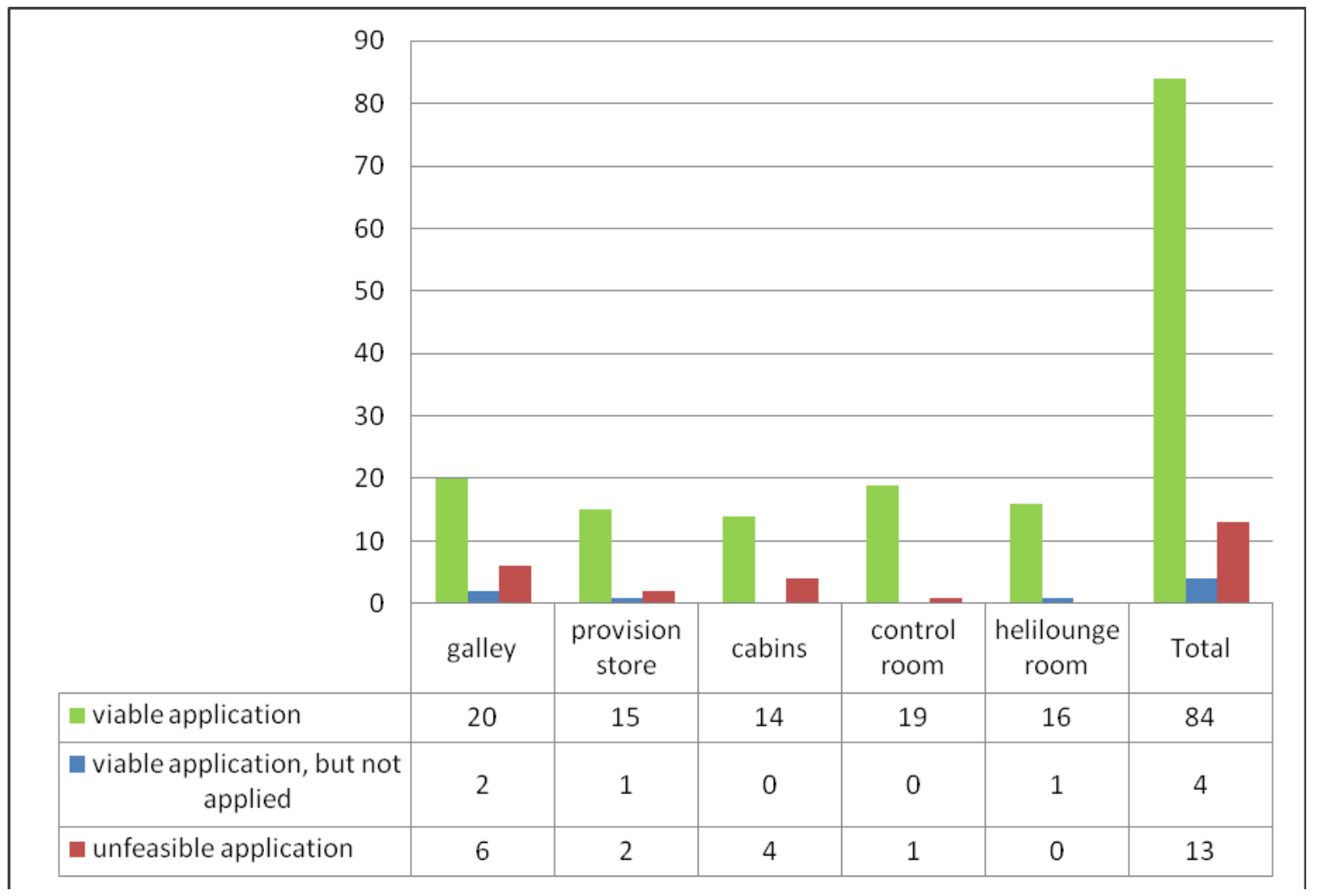

Fig. 2 - Map of ergonomic recommendations use in project

It was observed that the viability of use of the recommendations is high (almost 90\%). Even when it was not possible to use these recommendations, the settings of use served as a guide to understanding the real work activities, working as guidance to designer without limiting their creativity.
Thus, it was possible to propose layouts, equipments, and furnishings according to the specific design of the oil rigs of the case study. Even in its use in situations of reuse of houses, when the recommendation indicated a need that the project was limited to 
the structure reused, it was possible to circumvent the situation.

Throughout the project, negotiations were needed between the various stakeholders to accept the proposals of ergonomic study, which resulted in adjustments in layouts to increase the chance of implementation. But in some cases, it was not possible to overcome the "barrier" of the time the ergonomic study went into the project

Because this situation, the major reason for difficulties in the use the ergonomic proposals was the time. The ergonomic study went into the detailed design phase, and construction phase was also underway. Changes in this phase mean cost. And cost reduction was a major goal of this project.

In this phase, the design features were already known, but the possibility of action of the ergonomic study became reduced. That is, the margin for maneuver for changes in projects in this phase are very small, since the major decisions have been made [2].

Normally, when the objectives of production and investments are defined, the technical options are also set together, but the attention to future users needs only occurs in the final stages of design. The work is considered an adjustment variable and no action variable. But as action variable, the work offers real possibilities for improved performance and working conditions of operators [2]. Therefore, the application of ergonomics in the early stages of the design process is a necessity. The more the inscription is late, more its range is reduced [6].

If the application of ergonomics happens early in the project, or the stage of basic design in the case studied, it becomes possible reflection of management regarding the main options that configure the project, allowing the description and understanding of the interrelationships between different components of the project, increasing the ability to anticipate, and reducing, along the design process, uncertainties about the effectiveness of future operations $[2]$.

When questioning if the ergonomic recommendations based on experience from previous projects are still applicable to new projects, from the experience of the ergonomic study of the design of the platforms presented in the case study, the answer is yes.

Previous experiments that generated the recommendations are not lost, but its implementation will depend heavily on the time of entry into the project so that future work is not compromised. Previous experiments that generated the recommendations are not lost, but its implementation will depend heavily on the time of its consideration in the design for the future work is not compromised. In detailing phase, the possibilities of adjustment are very small, but its inclusion in the basic design would increase the possibilities for adaptation, since this phase is the time when the decisions that will set up the project are being taken.

\section{References}

[1] C. Conceição, F. Duarte, "Contribution of ergonomics to workspace sesign in the offshore accommodations module", in: SPE International Conference on Health, Safety and Environment in Oil and Gas Exploration and Production held, Rio de Janeiro, april, 2010.

[2] F. Duarte, "Complementaridade entre ergonomia e engenharia em projetos industriais", in: __. (Org.), Ergonomia e projeto na indústria de processo contínuo, Rio de Janeiro, Lucerna, 2002.

[3] F. Duarte et al, Recomendações técnicas: módulo de acomodações, in: A integração da ergonomia ao projeto de plataformas offshore, projeto PD-10573, Rio de Janeiro, agosto, 2009

[4] F. Daniellou, "A ergonomia na condução de projetos de concepção de sistemas de trabalho", in: P. Falzon (ed.), Ergonomia, São Paulo, Blucher, 2007, pp. 303-315.

[5] F. Guérin et al, Compreender o Trabalho para Transformá-lo A prática da Ergonomia, Tradução de Giliane Ingratta e Marcos Maffei, São Paulo, Blucher - Fundação Vanzolini, 2001.

[6] P. Béguin, "O ergonomista, ator da concepção", in: P. Falzon (ed.), Ergonomia, São Paulo, Blucher, 2007a, pp. 317-330.

[7] P. Béguin, "Prendre em compte l'activité de travail pour concevoir", Activités, v. 4, n. 2, 2007b, pp. 107-114.

[8] P. Béguin, "Argumentos para uma abordagem dialógica da inovação”, Laboreal, v. 4, n. 2, 2008, pp. 72-82.

[9] P. Béguin, F. Duarte, "A inovação: entre o trabalho dos projetistas e o trabalho dos operadores", Laboreal, v. 4, n. 2, , 2008, pp. 10-14.

[10]P. Béguin, 'L'ergonomie en conception : cristallisation, plasticité, développement", in: A. Hatchuel, B. Weil. (eds). Les nouveaux régimes de la conception, Langages, théories, métiers, Paris, Vuibert, 2009, pp 200-208.

[11]P. Falzon, "Natureza, objetivos e conhecimentos da ergonomia”, in: __ (ed.), Ergonomia, São Paulo, Blucher, 2007, pp. 3-20. 